\title{
INFLUÊNCIA DA COLHEITA E DO ARMAZENAMENTO NA QUALIDADE FISIOLÓGICA DE SEMENTES DE MAMONA ${ }^{1}$
}

\author{
SHEILA FANAN² ${ }^{2}$ PRISCILA FRATIN MEDINA³, MARCELO BENTO PAES DE CAMARGO4, \\ NILZA PATRÍCIA RAMOS 5
}

\begin{abstract}
RESUMO - Sabe-se que ao longo do ciclo da mamoneira são produzidos racemos de várias ordens que se desenvolvem sob diferentes condições ambientais, as quais podem provocar variações na qualidade das sementes no campo e durante o armazenamento. Assim, objetivou-se avaliar o efeito de diferentes tratamentos de colheita (ordens de racemos e épocas) e da armazenagem na qualidade fisiológica de sementes de mamona, cultivar IAC-2028. Foram instalados testes de germinação, emergência de plântulas em areia, velocidade de emergência e crescimento de plântulas, logo após a colheita e aos 3, 6, 9 e 12 meses de armazenamento em ambiente de laboratório, sem controle de temperatura e umidade relativa do ar. O delineamento experimental adotado foi em blocos ao acaso, com cinco repetições, em esquema de parcela subdividida, onde as parcelas foram constituídas por cinco períodos trimestrais de avaliação e as sub-parcelas de 11 tratamentos de colheita. Com base nos resultados obtidos, conclui-se que a colheita dos racemos de mamona da cultivar IAC-2028, nas condições deste experimento, pode ser realizada em uma única etapa sem que ocorram perdas de qualidade fisiológica das sementes e o armazenamento manteve satisfatoriamente a qualidade das mesmas.
\end{abstract}

Termos para indexação: Ricinus communis L., racemos, maturidade fisiológica, época de colheita.

\section{INFLUENCE OF HARVEST AND STORAGE ON PHYSIOLOGICAL QUALITY OF CASTOR BEAN SEEDS}

\begin{abstract}
Racemes are produced in several orders during the castor bean crop growth that develop under different environmental conditions which can cause variations in the seed quality in the field and during storage. This paper aimed to evaluate the effect of different harvest (racemes orders and harvest time) and storage treatments on the physiological quality of castor bean seeds, cultivar IAC-2028. Evaluation tests of germination, seedling emergence in sand, emergence speed and seedling growth were performed soon after harvest and at 3, 6, 9 and 12 months of storage under laboratory conditions and uncontrolled air temperature and relative humidity. The evaluations were carried out in a randomized block design with five replications in a split plot design, where the plots consisted of five 3-month evaluation periods and the sub-plots of eleven treatments. It was concluded that the castor bean seeds kept in the field did not deteriorate and storage maintained the quality of the seeds. All the racemes of the IAC-2028 castor bean cultivar can be harvested at a single time without seed quality losses
\end{abstract}

Index terms: Ricinus communis L., racemes, physiological maturity, harvest time.

\footnotetext{
${ }^{1}$ Submetido em 13/06/2008. Aceito para publicação em 24/11/2008. Parte da dissertação de mestrado apresentada pelo primeiro autor junto ao programa de pós-graduação em Agricultura Tropical e Subtropical do Instituto Agronômico (IAC), em 2008.
}

${ }^{2}$ Eng. Agr, IAC, Caixa Postal 28, CEP 13012-970 - Campinas - SP. E-mail: sheilafanan@yahoo.com.br. Bolsista FAPESP.
${ }^{2}$ Eng. Agr, Jardim Botânico do IAC. E-mail: pfmedina@iac.sp.gov.br ${ }^{4}$ Eng. Agr, Centro de Pesquisa e Desenvolvimento em Ecofisiologia e Biofísica do IAC. E-mail: mcamargo@iac.sp.gov.br. Bolsista CNPq.

${ }^{5}$ Eng. Agr, EMBRAPA, Rod. SP 340, Km 127,5, Caixa Postal 69, CEP 13820-000 - Jaguariúna - SP. E-mail: npramos@cnpma.embrapa.br 


\section{INTRODUÇÃO}

As sementes de mamona têm despertado grande interesse, devido ao incentivo à produção de biodiesel, o que exigirá grandes áreas de plantio para atender a demanda do mercado de combustíveis. No entanto, para que a ampliação da oferta dessa matéria-prima seja bem sucedida, é necessário desenvolver um conjunto de conhecimentos que permitam a obtenção de maior qualidade fisiológica e conservação das sementes, para que essa cultura faça frente a outras opções como a soja, o amendoim e o girassol, cuja tecnologia de produção é mais aprimorada. No Brasil, na safra de 2005/2006, a produtividade média das sementes da mamona foi de $703 \mathrm{Kg} / \mathrm{ha}$, ainda muito baixa considerando que na mesma safra a média de produtividade da soja foi de $2.419 \mathrm{Kg} / \mathrm{ha}$, a do amendoim de $2.367 \mathrm{Kg} / \mathrm{ha}$ e a do girassol de $1.399 \mathrm{Kg} / \mathrm{ha}$ (Conab, 2008).

De acordo com Freire et al. (2001) e Azevedo e Lima (2001), a baixa produtividade média da mamona observada no Brasil deve-se ao uso de sementes de baixa qualidade, multiplicadas pelos próprios agricultores, acarretando alto grau de heterogeneidade e grande diversidade de tipos locais. Segundo Savy Filho (2005), a produtividade também está relacionada ao plantio em época adequada; o melhor período para o plantio da mamoneira nas condições do Estado de São Paulo está situado entre outubro e novembro, propiciando bom suprimento e uniformidade nas precipitações pluviais, com temperatura média acima de $20^{\circ} \mathrm{C}$.

Os racemos não se desenvolvem ao mesmo tempo na planta, já que o florescimento da mamoneira é chamado botanicamente de simpodial, onde o aparecimento da inflorescência dá-se seqüencialmente, a intervalos médios de 20 a 35 dias entre a emissão das inflorescências primárias, secundárias e terciárias, acarretando em colheita parcelada, para as variedades deiscentes, à medida que os racemos vão amadurecendo, quando 2/3 dos frutos estão secos (Savy Filho, 2005).

Nesses casos, a colheita dos racemos, frutos e sementes da mamoneira é feita em várias etapas, periodicamente, com o intuito de minimizar os efeitos da desuniformidade de maturação e maximizar a qualidade das sementes (Gonçalves et al., 1981; Mazzani, 1983).

O Instituto Agronômico de Campinas - IAC lançou em janeiro de 2007 uma nova cultivar de mamona, a IAC-2028, de frutos indiscentes com elevados potenciais produtivos) entre $1.500 \mathrm{~kg}$ a $2.800 \mathrm{Kg} /$ ha nas condições do Estado de São Paulo, ciclo precoce que varia de 150 dias a 180 dias até a colheita dos racemos terciários e quaternários e teor de óleo de $47 \%$.

Para cultivares de frutos indeiscentes, cujos frutos não abrem depois de secos, nem na planta e nem no terreiro, a colheita é realizada numa única etapa, quando todos os cachos da planta já tiverem atingido a maturidade fisiológica, o que possibilita a mecanização dessa operação (Savy Filho et al., 2007).

Para a propagação desta espécie e cultivar, no caso da colheita única, é importante que se avaliem possíveis perdas de qualidade fisiológica das sementes, em função da sua permanência no campo, após a maturidade fisiológica ter sido atingida, já que, de acordo com Marcos Filho (2005), a maturidade fisiológica identifica o momento em que cessa a transferência de matéria seca da planta para as sementes, que nessa ocasião apresentam potencial fisiológico elevado senão máximo. O atraso da colheita, a partir desse ponto, acarreta sérios inconvenientes, determinados pela exposição relativamente elevada das sementes a condições menos favoráveis do ambiente, como a alternância de períodos secos e úmidos, aliada a temperaturas elevadas, podendo ocorrer queda do potencial fisiológico.

Diversos estudos, como o de Braccini et al. (2003), foram realizados objetivando avaliar o efeito da época de semeadura e de colheita sobre o potencial fisiológico das sementes de soja, de forma que para esta cultura já é bem conhecido que o período de permanência das sementes no campo, após a maturidade fisiológica ter sido atingida, é fator importante na deterioração e, portanto, determina queda no vigor. No entanto, não há informações a este respeito para sementes de mamona.

Ainda, de acordo com Carvalho e Nakagawa (2000), as sementes que apresentam menor potencial de armazenamento são as colhidas após o ponto de maturidade fisiológica, por já terem iniciado o processo de deterioração.

As sementes oleaginosas apresentam menor potencial de armazenamento que as amiláceas, devido à menor estabilidade química dos lipídios em relação ao amido, uma vez que uma elevação moderada da temperatura, como conseqüência do processo respiratório, já é suficiente para a decomposição dos lipídios e elevação da taxa de deterioração. Por esse motivo, as sementes de mamona devem ser armazenadas com grau de umidade inferior ao recomendado para as amiláceas (Marcos Filho, 2005), ou seja, entre 8 e 10\% (Gonçalves et al., 1981).

De acordo com Marcos Filho (2005), para a melhor conservação das sementes ortodoxas, como as de mamona, o ambiente com umidade relativa e temperatura mais baixa tem se mostrado adequado, já que essas condições permitem 
manutenção de baixo nível de atividade de reações químicas e preservação do poder germinativo e do vigor das sementes.

Assim, este trabalho teve por objetivo avaliar a influência de diferentes tratamentos de colheita (ordens dos racemos e épocas) e do armazenamento na qualidade fisiológica de sementes de mamona, cultivar IAC-2028.

\section{MATERIAL E MÉTODOS}

O experimento foi conduzido no município de Campinas (SP), localizado a $674 \mathrm{~m}$ de altitude, $22^{\circ} 54^{\prime}$ de latitude sul e $47^{\circ} 05^{\prime}$ de longitude oeste. O clima é caracterizado, segundo a classificação de Köppen, como sendo do tipo Cwa, tropical de altitude, com temperaturas médias mensais entre 15 e $22{ }^{\circ} \mathrm{C}$. No verão, as chuvas são mais intensas e no inverno há possibilidade de geadas. O experimento foi instalado no Centro Experimental Central do Instituto Agronômico de Campinas (IAC), em solo Argissolo e o preparo consistiu de adubação, seguindo-se as recomendações de Van Raij et al. (1997), de acordo com os resultados de análise de solo, sendo que o adubo foi aplicado no sulco, por ocasião da semeadura, na dosagem de $235 \mathrm{Kg} / \mathrm{ha}$, com a formulação 8-28-16.

Foi utilizada a cultivar IAC-2028demamona(Ricinus communis L.). A semeadura foi realizada em 19/12/2005, numa área de $3564 \mathrm{~m}^{2}$, sendo as parcelas constituídas por seis linhas de 11,0 m espaçadas de 1,8 m, desprezando-se como bordadura $0,5 \mathrm{~m}$ das extremidades e duas linhas laterais, formando uma área útil de $72 \mathrm{~m}^{2}$. Durante a condução da cultura foi deixada uma planta por metro linear. As plantas daninhas foram controladas com capinas manuais e não foi realizada irrigação complementar.

As parcelas foram distribuídas em delineamento experimental de blocos ao acaso, com cinco repetições e os tratamentos de colheita foram determinados da seguinte forma: 1-CRP = Colheita parcelada do racemo primário (163 e 201 dias após a semeadura); 1-CRS = Colheita parcelada do racemo secundário (163, 208 e 237 dias); 1-CRT = Colheita parcelada do racemo terciário (237 e 249 dias); $2-\mathbf{C R}(\mathbf{P}+\mathbf{S}+\mathbf{T})$ = Colheita parcelada dos racemos primário, secundário, terciário e sementes misturadas após a colheita do racemo terciário (163, 208, 237 e 249 dias); 3-CRP(S) = Colheita parcelada do racemo primário quando o ponto de colheita do racemo secundário foi alcançado (163, 208 e 237 dias); 3-CRS = Colheita parcelada do racemo secundário (163, 208 e 237 dias); $\mathbf{4 - C U}(\mathbf{P}+\mathbf{S})$ = Colheita única dos racemos primário e secundário, com sementes misturadas quando o ponto de colheita do racemo secundário foi atingido (163,
208 e 237 dias); 5-CRP(T) = Colheita parcelada do racemo primário quando o ponto de colheita do racemo terciário foi atingido (237 dias); 5-CRS(T) = Colheita parcelada do racemo secundário quando o ponto de colheita do racemo terciário foi atingido (237 dias); 5-CRT = Colheita parcelada do racemo terciário aos 237 dias; $\mathbf{6}-\mathbf{C U}(\mathbf{P}+\mathbf{S}+\mathbf{T})=$ Colheita única dos racemos primário, secundário e terciário, com sementes misturadas quando o ponto de colheita do racemo terciário foi atingido (237 e 249 dias).

No campo, os racemos referentes aos tratamentos 1-CRP, 1-CRS e 1-CRT foram obtidos de plantas de uma mesma parcela, o tratamento 2-CR(P+S+T) de outra, assim como os tratamentos 3-CRP(S) e 3-CRS; o 4-CU(P+S); os 5-CRP(T), 5-CRS(T) e 5-CRT e o tratamento 6-CU(P+S+T), totalizando onze tratamentos definidos em seis parcelas distribuídas em cada um dos cinco blocos. Assim, no tratamento1-CRS, os racemos secundários foram colhidos em plantas, em que o racemo primário já havia sido colhido anteriormente, diferindo do tratamento 3-CRS, em que os racemos secundários foram colhidos ao mesmo tempo em que o primário em uma mesma planta; da mesma forma, no tratamento1-CRT, os racemos (terciários foram colhidos em plantas em que o primário e os secundários já haviam sido colhidos anteriormente, diferindo do tratamento 5-CRT, em que os racemos primário, secundários e terciários foram colhidos ao mesmo tempo em uma mesma planta.

Foram colhidos os racemos da área útil das parcelas, quando 2/3 dos frutos estavam secos. No momento da colheita, os frutos apresentaram-se de coloração marrom e teor de água das sementes, em média, de 6,5\%. Esse ponto foi alcançado entre os dias 163 e 201 nos racemos primários, 163, 208 e 237 nos secundários; 237 e 249 dias nos racemos terciários, após a semeadura, sendo a data da última colheita em 25/08/2006, refletindo uma grande desuniformidade de estádio de maturação da cultura entre parcelas e blocos.

Os dados médios de precipitação pluvial $(\mathrm{mm})$ e de temperatura $\left({ }^{\circ} \mathrm{C}\right)$, observados durante a condução da cultura, bem como as épocas em que os racemos primários, secundários e terciários atingiram o ponto de colheita estão na Figura 1. Procedida à colheita, os racemos das plantas correspondentes a cada tratamento foram conduzidos ao Laboratório de Análise de Sementes do Instituto Agronômico - IAC, localizado em Campinas-SP, onde foram realizadas a remoção manual do pericarpo (casca) dos frutos, o armazenamento e a determinação da qualidade fisiológica das sementes.

As sementes foram armazenadas em sacos de papel Kraft, embalagem permeável a trocas gasosas e à água, em condição 
ambiente, no Laboratório de Análise de Sementes do IAC por 12 meses. Verificou-se que, durante o armazenamento das sementes, a temperatura mínima foi de $6,4^{\circ} \mathrm{C}$ e a máxima de $36,0^{\circ} \mathrm{C}$; já os valores da umidade relativa do ar variaram de 11,2 a $100 \%$. Foram realizadas avaliações trimestrais, tendose os dados de qualidade logo após a colheita (zero mês) e aos três, seis, nove e doze meses de armazenagem, aplicando os seguintes testes: grau de umidade (base úmida) - realizado em estufa a $105 \pm 3^{\circ} \mathrm{C} / 24 \mathrm{~h}$, constituído de duas subamostras por repetição com cerca de 6 g para cada tratamento (Brasil, 1992); germinação - cinco repetições de 50 sementes foram distribuídas em rolo de papel tipo Germitest, umedecido com água em quantidade equivalente a 2,5 vezes a massa do substrato seco, e colocados para germinar em temperatura alternada de $20-30^{\circ} \mathrm{C}$ e luz constante. As contagens foram realizadas aos sete e 14 dias após a semeadura e as avaliações efetuadas segundo os critérios estabelecidos pelas Regras para Análise de Sementes - RAS (Brasil, 1992); emergência de plântulas em areia - cinco repetições de 50 sementes por tratamento, semeando-se duas repetições em cada bandeja de plástico de $37 \times 26 \times 8 \mathrm{~cm}$, contendo areia fina esterilizada, a $4 \mathrm{~cm}$ de profundidade, umedecido a $60 \%$ da capacidade de retenção. Aos 28 dias foi realizada a contagem de plântulas normais emersas e, durante esse período, a umidade relativa e temperatura do ar foram registradas por termohigrógrafo; teste de tetrazólio - utilizou-se a metodologia descrita por
Brasil (1992) e por Delouche et al. (1976), nas sementes que permaneceram dormentes ou intumescidas no final do teste de germinação e de emergência de plântulas em areia. As sementes já hidratadas pelos testes foram cortadas longitudinalmente através do seu eixo embrionário e mantidas as duas extremidades da carúncula unidas para a avaliação. Após os cortes, as sementes foram colocadas em recipientes plásticos cobertas com solução do sal de tetrazólio $(0,5 \%)$ e mantidas em câmara escura à $40{ }^{\circ} \mathrm{C}$ por 4 horas. Passado esse tempo, removeu-se a solução de tetrazólio e as sementes foram lavadas com água. Os tecidos internos das sementes foram analisados para avaliação das sementes dormentes e mortas; índice de velocidade de emergência - conduzido em conjunto com o teste de emergência de plântulas em areia, computando-se diariamente, no mesmo horário, até o $28^{\circ}$ dia após a semeadura, o número de plântulas emersas (alça do hipocótilo visível) para cálculo do índice de velocidade de emergência, conforme descrito por Maguire (1962); comprimento de plântulas - utilizou-se metodologia descrita por Nakagawa (1994), conduzida com quatro amostras de 10 sementes por repetição, em substrato rolo de papel. Os rolos contendo as sementes permaneceram em temperatura alternada de $20-30{ }^{\circ} \mathrm{C}$, luz constante por 10 dias, sendo avaliado, posteriormente, o comprimento da raiz primária, da parte aérea (hipocótilo) e das plântulas, com resultados expressos em $\mathrm{cm}$.

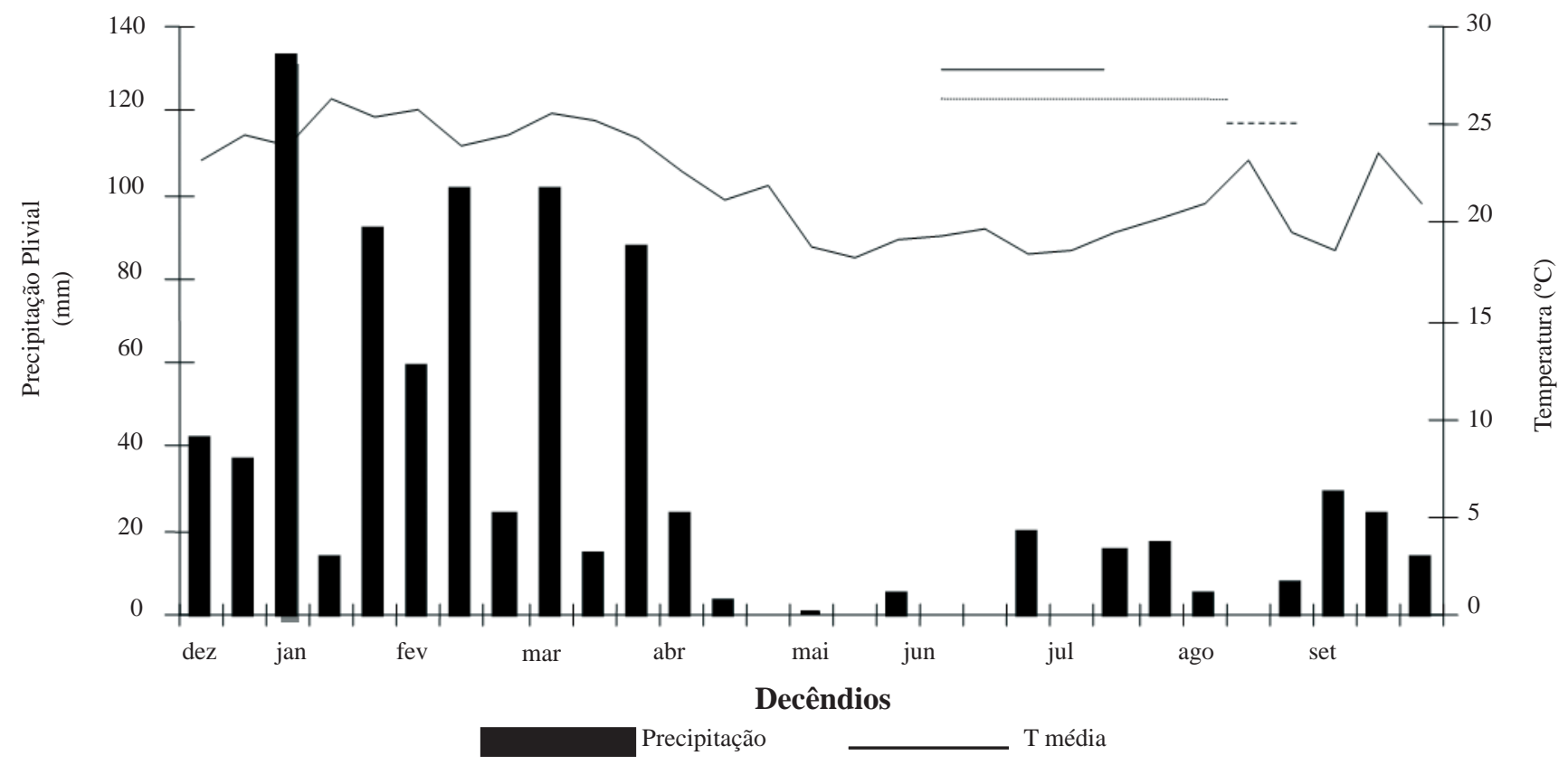

FIGURA 1. Épocas em que os racemos primário $($ ), secundário $(\rightarrow$ e terciário $(--)$ de mamona, cultivar IAC-2028, atingiram o ponto de colheita; totais de precipitação e média de temperatura do ar, em nível descendial, registradas entre o período de plantio e colheita, de dezembro/2005 a agosto/2006, em Campinas-SP. 
O delineamento experimental foi o de blocos ao acaso, com cinco repetições, com parcelas subdivididas. As parcelas foram constituídas por cinco períodos trimestrais de avaliação e as subparcelas de 11 tratamentos. Os dados foram submetidos à análise de variância, com comparação de médias pelo teste de Tukey em 5\% de probabilidade, empregandose o Programa de Análise estatística - SANEST (Zonta e Machado, 1987). Os dados em porcentagem dos testes de qualidade foram transformados em arco seno $\sqrt{ } \mathrm{x} / 100$, sendo que nas tabelas são apresentados os valores originais.

\section{RESULTADOS E DISCUSSÃO}

De acordo com as análises de variância, não foram observadas interações significativas $(\mathrm{P} \leq 0,05)$ entre os fatores tratamentos de colheita vs. períodos de armazenamento para todas as variáveis analisadas (germinação, emergência, índice de velocidade de emergência e comprimento de plântulas).

Os valores médios de germinação (plântulas normais), de sementes dormentes e de sementes vivas (soma da germinação com as sementes dormentes), armazenadas por cinco períodos em temperatura ambiente, encontram-se na Tabela 1.

TABELA 1. Porcentagem de germinação (G), sementes dormentes (D) e sementes vivas (V) de mamona, cultivar IAC2028, provenientes de diferentes tratamentos de colheita e armazenadas por 12 meses.

\begin{tabular}{|c|c|c|c|c|c|c|c|c|c|c|c|c|c|c|c|c|}
\hline \multirow[b]{3}{*}{ Tratamentos } & \multicolumn{16}{|c|}{ Meses de armazenamento } \\
\hline & \multicolumn{3}{|c|}{0} & \multicolumn{3}{|c|}{3} & \multicolumn{3}{|c|}{6} & \multicolumn{3}{|r|}{9} & \multicolumn{2}{|r|}{12} & \multicolumn{2}{|c|}{ Médias } \\
\hline & G & D & V & G & D & V & G & D & V & $\mathrm{G}$ & D & V & G D & D V & G D & $\mathrm{V}$ \\
\hline 1-CRP & 96 & 1 & 97 & 94 & 0 & 94 & 94 & 1 & 95 & 92 & 3 & 95 & 81 & 586 & $91 \mathrm{a} 2 \mathrm{a}$ & $3 a$ \\
\hline 1-CRS & 94 & 2 & 96 & 93 & 2 & 95 & 94 & 1 & 95 & 91 & 3 & 94 & 89 & 392 & $92 \mathrm{a} 2 \mathrm{a}$ & $94 \mathrm{a}$ \\
\hline 1-CRT & 92 & 4 & 96 & 94 & 0 & 94 & 92 & 1 & 93 & 93 & 3 & 96 & 86 & 591 & $91 \mathrm{a} 3 \mathrm{a}$ & $94 \mathrm{a}$ \\
\hline $2-\mathrm{CR}(\mathrm{P}+\mathrm{S}+\mathrm{T})$ & 92 & 2 & 94 & 98 & 0 & 98 & 92 & 0 & 92 & 88 & 8 & 96 & 81 & 889 & $90 \mathrm{a} 3 \mathrm{a}$ & $94 a$ \\
\hline 3-CRP(S) & 95 & 0 & 95 & 95 & 1 & 96 & 93 & 0 & 93 & 94 & 4 & 98 & 87 & 390 & $93 a 2 a$ & $94 a$ \\
\hline 3-CRS & 96 & 0 & 96 & 96 & 0 & 96 & 95 & 1 & 96 & 94 & 2 & 96 & 85 & 085 & $93 a 1 a$ & $94 a$ \\
\hline 4-CU(P+S) & 92 & 1 & 93 & 95 & 1 & 96 & 91 & 1 & 92 & 96 & 2 & 98 & 85 & 287 & $92 \mathrm{a} 1 \mathrm{a}$ & $93 a$ \\
\hline 5-CRP(T) & 95 & 0 & 95 & 96 & 0 & 96 & 93 & 0 & 93 & 90 & 8 & 98 & 95 & 196 & $94 a 2 a$ & $96 a$ \\
\hline 5-CRS(T) & 98 & 0 & 98 & 96 & 0 & 96 & 97 & 0 & 97 & 93 & 5 & 98 & 92 & 193 & $95 \mathrm{a} 1 \mathrm{a}$ & $96 a$ \\
\hline 5-CRT & 99 & 0 & 99 & 97 & 0 & 97 & 93 & 1 & 94 & 90 & 7 & 97 & 81 & 788 & $92 \mathrm{a} 3 \mathrm{a}$ & $95 a$ \\
\hline 6-CU(P+S+T) & 96 & 0 & 96 & 97 & 1 & 98 & 92 & 0 & 92 & 93 & 4 & 97 & 87 & 491 & $93 \mathrm{a} 2 \mathrm{a}$ & $95 \mathrm{a}$ \\
\hline Médias & $95 \mathrm{~A}$ & $1 \mathrm{~A}$ & $96 \mathrm{AB}$ & $95 \mathrm{AO}$ & $0.5 \mathrm{~A}$ & $6 \mathrm{AB}$ & $93 \mathrm{AB}$ & 0.5 & $\mathrm{~A} 4 \mathrm{BC}$ & $92 \mathrm{~B}$ & $4 \mathrm{~B}$ & $97 \mathrm{~A}$ & $86 \mathrm{C} 3$ & $3 B$ 90C & & \\
\hline $\mathrm{CV}$ (meses) (\%) & 2,4 & 28,8 & $8 \quad 2,7$ & & & & & & & & & & & & & \\
\hline $\mathrm{CV}$ (tratamentos) (\%) & 9,4 & 90,7 & $7 \quad 8,8$ & & & & & & & & & & & & & \\
\hline
\end{tabular}

Médias seguidas de mesma letra, maiúscula na linha e minúscula na coluna, não diferem entre si pelo teste de Tukey em 5\% de probabilidade.

Pelos padrões nacionais para produção e comercialização de sementes de mamona (Brasil, 2005), a porcentagem de germinação mínima deve ser de $80 \%$ para sementes básicas e de $85 \%$ para as certificadas de primeira e de segunda geração e para as sementes S1 e S2. Verificou-se que, nas médias dos períodos de armazenamento e tratamentos de colheita, esses níveis foram superados. A partir dos seis meses, no entanto, constatou-se uma queda na porcentagem média de germinação das sementes, que não afetou consideravelmente sua qualidade, já que a germinação permaneceu acima de 85\%, mesmo quando armazenadas por 12 meses. A porcentagem média de sementes vivas foi superior a $90 \%$ para todos os períodos de armazenamento, o que indicou que as condições de armazenamento não foram prejudiciais à qualidade das sementes, pois, de acordo com Marcos Filho (2005), a ação conjunta de altas umidades relativas e temperaturas aceleram o processo de deterioração de sementes ortodoxas como a mamona, reduzindo-lhes a longevidade.

A alta porcentagem inicial de germinação das sementes, de 92 a 99\%, indica que as condições climáticas, observadas 
durante o período em que as sementes permaneceram no campo até a colheita, não foram prejudiciais a sua qualidade. Neste período, ocorreu baixa precipitação $(67 \mathrm{~mm})$ e temperatura $\left(19,9^{\circ} \mathrm{C}\right)$, de forma que as sementes de todos os tratamentos foram colhidas com teores de água em torno de 6,5\% (Tabela 2), o que foi mantido durante os 12 meses de armazenamento. Portanto, as condições em que as sementes foram mantidas no campo (Figura 1) e no armazém, após terem atingido o ponto de colheita, não contribuíram para a sua deterioração. Com isso, houve uma uniformidade na qualidade das sementes, independentemente da época de colheita, o que provavelmente não ocorreria se as condições ambientais tivessem sido adversas.

TABELA 2. Teor de água (\%) de sementes de mamona, cultivar IAC-2028, provenientes de diferentes tratamentos de colheita e armazenadas por 12 meses.

\begin{tabular}{|c|c|c|c|c|c|}
\hline \multirow[b]{2}{*}{ Tratamentos } & \multicolumn{5}{|c|}{ Meses de armazenamento } \\
\hline & 0 & 3 & 6 & 9 & 12 \\
\hline 1-CRP & 6,6 & 6,6 & 6,7 & 6,9 & 6,3 \\
\hline 1-CRS & 6,5 & 6,4 & 6,5 & 6,8 & 6,2 \\
\hline 1-CRT & 6,4 & 6,4 & 6,5 & 6,8 & 6,1 \\
\hline $2-\mathrm{CR}(\mathrm{P}+\mathrm{S}+\mathrm{T})$ & 6,5 & 6,4 & 6,6 & 6,9 & 6,2 \\
\hline 3-CRP(S) & 6,5 & 6,5 & 6,6 & 6,8 & 6,2 \\
\hline 3-CRS & 6,6 & 6,3 & 6,5 & 6,7 & 6,2 \\
\hline 4-CU(P+S) & 6,6 & 6,4 & 6,6 & 6,8 & 6,3 \\
\hline 5-CRP(T) & 6,4 & 6,4 & 6,5 & 6,6 & 6,2 \\
\hline 5-CRS(T) & 6,2 & 6,3 & 6,4 & 6,5 & 6,0 \\
\hline 5-CRT & 6,5 & 6,4 & 6,5 & 6,7 & 6,1 \\
\hline 6-CU(P+S+T) & 6,3 & 6,3 & 6,4 & 6,5 & 6,0 \\
\hline Médias & 6,5 & 6,4 & 6,5 & 6,7 & 6,2 \\
\hline
\end{tabular}

Dessa forma, não houve diferença significativa entre colher o racemo primário separadamente (1-CRP) e colhêlo quando o secundário alcançou o seu ponto de colheita (3-CRP(S)), assim como quando o racemo terciário atingiu seu momento de colheita (5-CRP(T)); o mesmo se aplica entre colher o racemo secundário separadamente (1-CRS e 3-CRS) e colhê-lo quando o terciário atingiu o seu ponto de colheita (5-CRS (T)).

O tratamento 6-CU $(\mathrm{P}+\mathrm{S}+\mathrm{T})$ reforçou ainda mais a hipótese de que a colheita única pode ser realizada em contraposição à parcelada, já que apresentou porcentagens de sementes germinadas, dormentes e vivas, semelhantes às do tratamento $2-\mathrm{CR}(\mathrm{P}+\mathrm{S}+\mathrm{T})$ para os cinco períodos de armazenagem.

Os dados médios das porcentagens de emergência e de sementes vivas, e do índice de velocidade de emergência estão na Tabela 3.

Observou-se que não houve diferença estatística na porcentagem média de emergência de plântulas entre os períodos de armazenagem. No entanto, somente ao zero mês essa porcentagem ficou acima de $85 \%$, o mínimo exigido para a produção e comercialização de sementes de mamona. $\mathrm{Na}$ avaliação de sementes vivas, detectadas pelo teste de tetrazólio, esse valor foi superado somente nos dois primeiros períodos de armazenamento para todos os tratamentos avaliados.

Enquanto as médias de germinação e de sementes vivas encontradas pelo teste de germinação foram acima de $90 \%$ para cada tratamento de colheita, durante os cinco períodos de armazenamento, no teste de emergência de plântulas esses valores ficaram abaixo de $90 \%$, sendo que a média geral menor foi de $76 \%$ para o tratamento 5-CRT (colheita 
parcelada do racemo terciário).

A maior porcentagem média de emergência de plântulas foi encontrada no tratamento 3-CRS (colheita parcelada do racemo secundário), de 88\% e valores intermediários para o restante dos tratamentos.
No entanto, ao se avaliar a porcentagem de sementes vivas, assim como no teste de germinação, não houve diferença estatística entre os tratamentos de colheita, durante os 12 meses de armazenagem, que apresentaram porcentagens acima de $84 \%$.

TABELA 3. Porcentagem de emergência (PE), índice de velocidade de emergência (IVE) e porcentagem de sementes vivas (V) de mamona, cultivar IAC-2028, provenientes de diferentes tratamentos de colheita e armazenadas por 12 meses.

\begin{tabular}{|c|c|c|c|c|c|c|c|c|c|c|c|c|}
\hline \multirow[b]{3}{*}{ Tratamentos } & \multicolumn{12}{|c|}{ Meses de armazenamento } \\
\hline & 0 & \multicolumn{3}{|c|}{3} & \multicolumn{3}{|c|}{6} & 9 & 12 & \multicolumn{3}{|c|}{ Médias } \\
\hline & PE IVE V & $\mathrm{PE}$ & IVE & $\mathrm{V}$ & PE & IVE & $\mathrm{V}$ & PE IVE $\mathrm{V}$ & PE IVE V & $\mathrm{PE}$ & IVE & $\mathrm{V}$ \\
\hline 1-CRP & $87 \quad 5,2 \quad 94$ & 82 & 5,2 & 90 & 78 & 5,0 & 85 & $67 \quad 4,273$ & $80 \quad 5,281$ & $79 a b$ & $4,9 \mathrm{ab}$ & $85 \mathrm{a}$ \\
\hline 1-CRS & $\begin{array}{lll}87 & 4,8 & 95\end{array}$ & 84 & 5,3 & 93 & 77 & 4,8 & 77 & 795,179 & 795,079 & $81 \mathrm{ab}$ & $5,0 \mathrm{ab}$ & $85 \mathrm{a}$ \\
\hline 1-CRT & $\begin{array}{lll}80 & 4,9 & 92\end{array}$ & 73 & 4,6 & 85 & 79 & 4,8 & 84 & 905,691 & 754,676 & $79 \mathrm{ab}$ & $4,9 \mathrm{ab}$ & $86 a$ \\
\hline $2-\mathrm{CR}(\mathrm{P}+\mathrm{S}+\mathrm{T})$ & $\begin{array}{lll}84 & 4,9 & 94\end{array}$ & 84 & 5,4 & 90 & 80 & 5,1 & 85 & $\begin{array}{lll}78 & 4,8 & 81\end{array}$ & 664,268 & $78 \mathrm{ab}$ & $4,9 \mathrm{ab}$ & $84 \mathrm{a}$ \\
\hline 3-CRP(S) & $94 \quad 6,0 \quad 98$ & 84 & 5,5 & 92 & 72 & 4,4 & 77 & $74 \quad 4,576$ & 875,688 & $82 \mathrm{ab}$ & $5,2 \mathrm{ab}$ & $86 \mathrm{a}$ \\
\hline 3-CRS & $\begin{array}{lll}93 & 5,8 \quad 96\end{array}$ & 93 & 6,0 & 94 & 90 & 5,5 & 91 & 744,675 & $\begin{array}{lll}88 & 5,5 & 88\end{array}$ & $88 \mathrm{a}$ & $5,5 \mathrm{a}$ & $89 \mathrm{a}$ \\
\hline 4-CU(P+S) & $\begin{array}{lll}86 & 5,8 \quad 95\end{array}$ & 85 & 5,6 & 87 & 86 & 5,3 & 88 & $83 \quad 5,184$ & 865,186 & $85 \mathrm{ab}$ & $5,4 \mathrm{ab}$ & $88 \mathrm{a}$ \\
\hline 5-CRP(T) & $\begin{array}{lll}86 & 5,6 \quad 89\end{array}$ & 94 & 6,3 & 94 & 82 & 5,1 & 85 & 815,181 & 855,185 & $86 \mathrm{ab}$ & 5,4 a & $87 \mathrm{a}$ \\
\hline 5-CRS(T) & $\begin{array}{lll}80 & 5,3 \quad 96\end{array}$ & 81 & 5,2 & 83 & 79 & 5,1 & 82 & $82 \quad 5,0 \quad 84$ & $85 \quad 5,285$ & $81 \mathrm{ab}$ & $5,2 \mathrm{ab}$ & $86 \mathrm{a}$ \\
\hline 5-CRT & $\begin{array}{lll}80 & 4,6 & 93\end{array}$ & 73 & 4,7 & 92 & 76 & 4,6 & 79 & $\begin{array}{lll}75 & 4,8 & 77\end{array}$ & $77 \quad 4,7 \quad 78$ & $76 \mathrm{~b}$ & $4,7 \mathrm{~b}$ & $84 \mathrm{a}$ \\
\hline 6-CU(P+S+T) & $84 \quad 5,2 \quad 93$ & 81 & 5,2 & 84 & 76 & 4,7 & 76 & $\begin{array}{lll}79 & 4,9 & 82 \\
\end{array}$ & $\begin{array}{lll}83 & 4,8 & 84 \\
\end{array}$ & $81 \mathrm{ab}$ & $5,0 \mathrm{ab}$ & $84 \mathrm{a}$ \\
\hline Médias & 86A 5,3A 94A & $82 \mathrm{~A} 5$ &, $4 \mathrm{~A} 8$ & 89AB & $79 \mathrm{~A}$ & $4,9 \mathrm{~A}$ & 83 & $3 \mathrm{~A} 4,9 \mathrm{~A} 80$ & $0 \mathrm{~A} \quad 5,0 \mathrm{~A} 82 \mathrm{BC}$ & & & \\
\hline CV (meses) (\%) & $7,5 \quad 9,4 \quad 5,4$ & & & & & & & & & & & \\
\hline $\begin{array}{c}\mathrm{CV} \text { tratamentos) } \\
(\%)\end{array}$ & $13,7 \quad 16,5 \quad 12,4$ & & & & & & & & & & & \\
\hline
\end{tabular}

Médias seguidas de mesma letra, maiúscula na linha e minúscula na coluna, não diferem entre si pelo teste de Tukey em 5\% de probabilidade

Em relação à avaliação do vigor das sementes, a diferenciação estatística entre os tratamentos, quanto ao índice de velocidade de germinação, foi semelhante à encontrada para a porcentagem de emergência de plântulas, ficando o maior índice, de 5,5 para o tratamento 3-CRS e o menor, de 4,7, para o 5-CRT (Tabela 3).

Esses resultados de percentagem e velocidade de emergência indicam que os tratamentos de colheita não afetaram a qualidade das sementes, com exceção do tratamento 5-CRT. O vigor das sementes também não foi prejudicado durante o armazenamento, já que o índice de velocidade de emergência foi semelhante estatisticamente durante os cinco períodos de armazenagem. A manutenção do vigor também pode ser explicada pelo fato de que o teor de água das sementes se manteve relativamente baixo, entre 6,2 e $6,7 \%$, em todos os tratamentos durante os 12 meses de armazenamento (Tabela 2).

Na Tabela 4 são encontradas as médias de comprimento do hipocótilo, do sistema radicular e da plântula, oriunda de sementes dos diferentes tratamentos, armazenadas por cinco períodos. No início do armazenamento, ao zero mês, as plântulas de todos os tratamentos apresentaram o menor comprimento do hipocótilo, do sistema radicular e total, em relação aos demais períodos. Verificou-se que aos nove meses essa situação foi alterada, constatando-se plântulas com maior hipocótilo e comprimento total. 
TABELA 4. Comprimento (cm) do hipocótilo, da raiz primária e da plântula de mamona, cultivar IAC-2028, proveniente de sementes de diferentes tratamentos de colheita e armazenada por 12 meses.

\begin{tabular}{|c|c|c|c|c|c|c|c|}
\hline \multirow{2}{*}{$\begin{array}{c}\text { Comprimentos } \\
(\mathrm{cm})\end{array}$} & \multirow[t]{2}{*}{ Tratamentos } & \multicolumn{5}{|c|}{ Meses de armazenamento } & \multirow[b]{2}{*}{ Médias } \\
\hline & & 0 & 3 & 6 & 9 & 12 & \\
\hline \multirow{12}{*}{ Hipocótilo } & 1-CRP & 3,9 & 3,8 & 5,6 & 6,1 & 4,8 & 4,8 bcde \\
\hline & 1-CRS & 3,1 & 4,1 & 5,3 & 5,3 & 4,4 & $4,4 \mathrm{e}$ \\
\hline & 1-CRT & 3,0 & 4,3 & 5,4 & 5,7 & 4,8 & $4,6 \mathrm{de}$ \\
\hline & $2-\mathrm{CR}(\mathrm{P}+\mathrm{S}+\mathrm{T})$ & 3,7 & 4,6 & 5,7 & 5,4 & 4,2 & 4,7 cde \\
\hline & 3-CRP(S) & 4,1 & 4,8 & 6,1 & 6,1 & 5,1 & $5,2 \mathrm{abc}$ \\
\hline & 3-CRS & 3,9 & 4,4 & 5,3 & 5,9 & 4,5 & 4,8 bcde \\
\hline & 4-CU(P+S) & 4,3 & 4,8 & 5,8 & 6,3 & 5,2 & $5,3 \mathrm{ab}$ \\
\hline & 5-CRP(T) & 3,8 & 5,0 & 6,3 & 6,8 & 5,6 & $5,5 \mathrm{a}$ \\
\hline & 5-CRS(T) & 3,3 & 4,3 & 5,7 & 5,7 & 4,9 & 4,8 bcde \\
\hline & 5-CRT & 3,9 & 4,5 & 5,4 & 5,2 & 4,2 & $4,6 \mathrm{de}$ \\
\hline & 6-CU(P+S+T) & 4,2 & 4,4 & 5,9 & 5,8 & 4,7 & $5,0 \mathrm{abcd}$ \\
\hline & Médias & $3,7 \mathrm{C}$ & 4,4 BC & $5,7 \mathrm{~A}$ & $5,9 \mathrm{~A}$ & $4,8 \mathrm{~B}$ & \\
\hline \multirow{12}{*}{ Raiz primária } & 1-CRP & 15,1 & 18,6 & 17,0 & 21,0 & 21,4 & $18,6 \mathrm{bc}$ \\
\hline & 1-CRS & 13,4 & 19,1 & 16,3 & 19,2 & 21,2 & $17,9 \mathrm{c}$ \\
\hline & 1-CRT & 12,3 & 19,4 & 16,9 & 19,3 & 21,4 & $17,9 \mathrm{c}$ \\
\hline & $2-\mathrm{CR}(\mathrm{P}+\mathrm{S}+\mathrm{T})$ & 14,4 & 19,6 & 18,3 & 18,4 & 19,0 & $17,9 \mathrm{c}$ \\
\hline & 3-CRP(S) & 15,1 & 21,4 & 18,9 & 21,1 & 22,5 & $19,8 \mathrm{ab}$ \\
\hline & 3-CRS & 15,7 & 20,4 & 16,2 & 20,2 & 19,5 & $18,4 \mathrm{bc}$ \\
\hline & 4-CU(P+S) & 16,1 & 21,6 & 17,5 & 21,8 & 22,5 & $19,9 \mathrm{ab}$ \\
\hline & 5-CRP(T) & 15,8 & 22,1 & 19,6 & 21,6 & 23,0 & $20,4 \mathrm{a}$ \\
\hline & 5-CRS(T) & 14,5 & 21,5 & 17,0 & 20,3 & 22,7 & $19,2 \mathrm{abc}$ \\
\hline & 5-CRT & 15,4 & 19,5 & 15,6 & 19,2 & 19,6 & $17,9 \mathrm{c}$ \\
\hline & 6-CU(P+S+T) & 15,6 & 20,6 & 18,5 & 20,8 & 21,0 & $19,3 \mathrm{abc}$ \\
\hline & Médias & $14,8 \mathrm{C}$ & $20,3 \mathrm{~A}$ & $17,4 \mathrm{~B}$ & $20,3 \mathrm{~A}$ & $21,2 \mathrm{~A}$ & \\
\hline \multirow{12}{*}{ Plântula } & 1-CRP & 19,0 & 22,4 & 22,6 & 27,1 & 26,2 & $23,5 \mathrm{bc}$ \\
\hline & 1-CRS & 16,5 & 23,3 & 21,7 & 24,5 & 25,5 & $22,3 \mathrm{c}$ \\
\hline & 1-CRT & 15,3 & 23,5 & 22,4 & 25,1 & 26,0 & $22,5 \mathrm{c}$ \\
\hline & $2-\mathrm{CR}(\mathrm{P}+\mathrm{S}+\mathrm{T})$ & 18,1 & 24,2 & 24,1 & 23,9 & 23,2 & $22,7 \mathrm{c}$ \\
\hline & 3-CRP(S) & 19,2 & 26,2 & 25,0 & 27,2 & 27,6 & $25,0 \mathrm{ab}$ \\
\hline & 3-CRS & 19,6 & 24,8 & 21,5 & 26,1 & 24,0 & $23,2 \mathrm{bc}$ \\
\hline & 4-CU(P+S) & 20,4 & 26,4 & 23,4 & 28,1 & 27,7 & $25,2 \mathrm{ab}$ \\
\hline & 5-CRP(T) & 19,6 & 27,1 & 25,9 & 28,5 & 28,6 & 25,9 a \\
\hline & 5-CRS(T) & 17,8 & 25,8 & 22,7 & 26,5 & 27,5 & $24,1 \mathrm{abc}$ \\
\hline & 5-CRT & 19,3 & 23,8 & 21,0 & 24,4 & 23,8 & $22,5 \mathrm{c}$ \\
\hline & 6-CU(P+S+T) & 19,6 & 24,9 & 24,4 & 26,6 & 25,8 & $24,3 \mathrm{abc}$ \\
\hline & Médias & $18,6 \mathrm{C}$ & $24,8 \mathrm{AB}$ & $23,1 \mathrm{~B}$ & $26,2 \mathrm{~A}$ & $26,0 \mathrm{~A}$ & \\
\hline
\end{tabular}

${ }^{1}$ Médias seguidas de mesma letra, maiúscula na linha e minúscula na coluna, não diferem entre si pelo teste de Tukey em 5\% de probabilidade. ${ }^{(2)} \mathrm{CV}$ (meses) $=8,8 \%$ e CV $($ tratamentos $)=11,9 \% .{ }^{(3)} \mathrm{CV}$ (meses) $=5,6 \%$ e CV $($ tratamentos $)=9,8 \% .{ }^{(4)} \mathrm{CV}($ meses $)=5,4 \%$ e CV $($ tratamentos $)=9,4 \%$. 
Observou-se que os resultados de comprimento de plântulas ao longo do armazenamento não seguiram um comportamento lógico de redução progressiva do vigor ou mesmo manutenção deste, havendo situações como as verificadas para o comprimento do hipocótilo que aumentou de tamanho com o armazenamento do zero aos nove meses; ou do sistema radicular que diminuiu de tamanho aos seis meses e aos nove tornou a aumentar; ou mesmo do comprimento total que diminuiu aos seis meses, tornou a aumentar aos nove e praticamente se manteve inalterado até os 12 meses de armazenamento.

A obtenção de plântulas menores oriundas de sementes recém-colhidas provavelmente resultou de uma manifestação da dormência residual das sementes, que não impediu a germinação, mas tornou o processo mais lento e desuniforme, o que pode ter interferido na avaliação do vigor, já que, de acordo com Marcos Filho (2005), a dormência apresenta profundidade inversamente proporcional à sua idade, ou seja, é mais intensa em sementes recém-colhidas. Dessa forma, a sua superação gradativa, à medida que a semente envelheceu, resultou em plântulas mais desenvolvidas e com maior uniformidade de tamanho, por ocasião da avaliação, levando a uma falsa impressão de aumento de vigor.

Com isso, as sementes mais velhas, isto é, as provenientes dos tratamentos que envolveram a colheita atrasada dos racemos, inclusive os tratamentos de colheita única, apresentaram comprimentos do hipocótilo, do sistema radicular e total das plântulas semelhantes estatisticamente ao tratamento de maior tamanho (5-CRP(T)), com exceção do 5-CRS(T) que não foi semelhante estatisticamente somente em relação ao comprimento do hipocótilo.

Já as sementes mais novas, provenientes dos tratamentos que envolveram a colheita dos racemos quando estes atingiram o seu ponto de colheita, inclusive o tratamento de colheita parcelada dos racemos $(2-\mathrm{CR}(\mathrm{P}+\mathrm{S}+\mathrm{T}))$, apresentaram comprimentos do hipocótilo, do sistema radicular e total das plântulas semelhantes estatisticamente ao tratamento de menor tamanho (1-CRS).

\section{CONCLUSÕES}

Nas condições deste experimento, pode-se concluir que: Sementes de mamona, cultivar IAC-2028, mantêm satisfatoriamente a sua qualidade fisiológica, durante 12 meses de armazenamento.

A colheita dos racemos primários, secundários e terciários pode ser realizada em uma única etapa, sem que ocorra perda de qualidade fisiológica das sementes.

\section{AGRADECIMENTOS}

Os autores agradecem à Fapesp(FAPESP) pela concessão de bolsa de Pós-graduação para Sheila Fanan e suporte financeiro nesta pesquisa, e ao $\mathrm{CNPq}$ pela bolsa em Produtividade Científica para Marcelo Bento Paes de Camargo.

\section{REFERÊNCIAS}

AZEVEDO, D.M.P; LIMA, E.F. O agronegócio da mamona no Brasil. Brasília, DF: Embrapa Informação Tecnológica, 2001. $350 \mathrm{p}$.

BRACCINI, A.L.; MOTTA, I.S.; SCAPIM, C.A.; BRACCINI, M.C.L.; ÁVILA, M.R.; SCHUAB, S.R.P. Semeadura da soja no período de safrinha: potencial fisiológico e sanidade das sementes. Revista Brasileira de Sementes, v.25, n.1, p.76-86, 2003.

BRASIL. Diário Oficial da União. Padrões para produção e comercialização de sementes de mamona. Brasília, DF, n²43, 2005. Seção 1, p.21-22

BRASIL. Ministério da Agricultura e da Reforma Agrária. Regras para análise de sementes. Brasília, DF: SNDA/ DNPV/CLAV, 1992. 365p.

CARVALHO, N.M.; NAKAGAWA, J. Sementes: ciência, tecnologia e produção. 4.ed. Jaboticabal: FUNEP, 2000. 588p.

CONAB - COMPANHIA NACIONAL DE ABASTECIMENTO. Mamona Brasil: série histórica de produtividade(safras1976/77a2007/08). Disponível em: $\quad<$ http://www.conab.gov.br/conabweb/dowload/safra/ mamonaseriehist.xls.>. Acesso em: 30 de set. 2008.

DELOUCHE, J.C.; STILL, T.W.; RASPET, M.; LIENHARD, M. O teste de tetrazólio para viabilidade da semente. Brasília: AGIPLAN, 1976. 103p.

FREIRE, E.C.; LIMA, E.F.; ANDRADE, F.P. Melhoramento genético. In: AZEVEDO, D.M.P. de; LIMA, E.F. (Ed.). O agronegócio da mamona no Brasil. Brasília: Embrapa Informação Tecnológica, 2001. p.229-256.

GONÇALVES, N.P.; BENDEZÙ, J.M.; LIMA, C.A.S. Colheita e armazenamento da mamona. Informe Agropecuário, v.82, n.7, p.44-45, 1981.

MAGUIRE, J.D. Speeds of germination - aid in selection 
and evaluation for seedling emergence and vigor. Crop Science, v.2, n.2, p.176-177, 1962.

MARCOS FILHO, J. Deterioração de sementes. In: MARCOS FILHO, J. (Ed.). Fisiologia de sementes de plantas cultivadas. Piracicaba: FEALQ, 2005. p. 291-348.

MAZZANI, B. Euforbiáceas oleaginosas. Tártago. In: MAZZANI, B. (Ed.). Cultivo y mejoramiento de plantas oleaginosas. Caracas: Fondo Nacional de Investigaciones Agropecuarias, 1983. p. 277-360.

NAKAGAWA, J. Testes de vigor baseados na avaliação das plântulas. In: VIEIRA, R.D.; CARVALHO, N.M. (Ed.). Testes de vigor em sementes. Jaboticabal: FUNEP, 1994. p. 49-85.
SAVY FILHO, A.; AMORIM, E.P.; RAMOS, N.P.; MARTINS, A.L.M.; CAVICHIOLI, J.C. IAC-2028: nova cultivar de mamona. Pesquisa Agropecuária Brasileira, v.42, n.3, p.449-452, 2007.

SAVY FILHO, A. Mamona: tecnologia agrícola. Campinas: EMOPI, 2005. 105p.

VAN RAIJ, B.; CANTARELLA, H.; QUAGGIO, J.A.; FURLANI, A.M.C. Recomendações de adubação e calagem para o Estado de São Paulo. Campinas, 1997. p.187-202.

ZONTA, E.P.; MACHADO, A.A. Sistema de análise estatística para microcomputadores: manual de utilização. 2.ed. Pelotas: UFP, 1987. 177p. 